\title{
Social norms towards smoking and electronic cigarettes among adult smokers in seven European Countries: Findings from the EUREST-PLUS ITC Europe Surveys
}

\author{
Katherine A. East ${ }^{1,2}$, Sara C. Hitchman ${ }^{1,2}$, Mairtin McDermott ${ }^{1}$, Ann McNeill ${ }^{1,2}$, Aleksandra Herbeć ${ }^{2,3,4}$, Yannis Tountas $^{5}$, \\ Nicolas Bécuwe ${ }^{6}$, Tibor Demjén ${ }^{7}$, Marcela Fu ${ }^{8,9}$, Esteve Fernández ${ }^{8,9}$, Ute Mons ${ }^{10}$, Antigona C. Trofor ${ }^{11,12}$, Witold A. \\ Zatoński3,13, Geoffrey T. Fong ${ }^{14,15}$, Constantine I. Vardavas ${ }^{16,17}$, on behalf of the EUREST-PLUS consortium*
}

\begin{abstract}
INTRODUCTION This study explores whether current smokers' social norms towards smoking and electronic cigarettes (e-cigarettes) vary across seven European countries alongside smoking and e-cigarette prevalence rates. At the time of surveying, England had the lowest current smoking prevalence and Greece the highest. Hungary, Romania and Spain had the lowest prevalence of any e-cigarette use and England the highest.

METHODS Respondents were adult ( $\geq 18$ years) current smokers from the 2016 EUREST-PLUS ITC (Romania, Spain, Hungary, Poland, Greece, Germany) and ITC 4CV England Surveys $(\mathrm{N}=7779)$. Using logistic regression, associations between country and (a) smoking norms and (b) e-cigarette norms were assessed, adjusting for age, sex, income, education, smoking status, heaviness of smoking, and e-cigarette status.

RESULTS Compared with England, smoking norms were higher in all countries: reporting that at least three of five closest friends smoke ( $19 \%$ vs $65-84 \%$ [AOR=6.9-24.0; Hungary-Greece]), perceiving that people important to them approve of smoking ( $8 \%$ vs 14-57\% [1.9-51.1; Spain-Hungary]), perceiving that the public approves of smoking (5\% vs $6-37 \%$ [1.7-15.8; Spain-Hungary]), disagreeing that smokers are marginalised (9\% vs 16-50\% [2.3-12.3; Poland-Greece]) except in Hungary. Compared with England: reporting that at least one of five closest friends uses e-cigarettes was higher in Poland (28\% vs $36 \%$ [2.7]) but lower in Spain and Romania (28\% vs $6-14 \%$ [0.3-0.6]), perceiving that the public approves of e-cigarettes was higher in Poland, Hungary and Greece (32\% vs $36-40 \%$ [1.5-1.6]) but lower in Spain and Romania in unadjusted analyses only ( $32 \%$ vs $24-26 \%$ ), reporting seeing e-cigarette use in public at least some days was lower in all countries $(81 \%$ vs $12-55 \%$ [0.1-0.4]; Spain-Greece).

concLusions Smokers from England had the least pro-smoking norms. Smokers from Spain had the least pro-e-cigarette norms. Friend smoking and disagreeing that smokers are marginalised broadly aligned with country-level current smoking rates. Seeing e-cigarette use in public broadly aligned with countrylevel any e-cigarette use. Generally, no other norms aligned with product prevalence.
\end{abstract}

\section{AFFILIATION}

1 National Addiction Centre, Institute of Psychiatry, Psychology and Neuroscience, King's College London, London, United Kingdom

2 UK Centre for Tobacco and Alcohol Studies, King's College London (KCL), London, United Kingdom

3 Health Promotion Foundation (HPF), Warsaw, Poland 4 Department of Behavioural Science and Health, University College London, London, United Kingdom 5 National and Kapodistrian University of Athens (UoA), Athens, Greece

6 Kantar Public (TNS), Brussels, Belgium

7 Smoking or Health Hungarian Foundation (SHHF),

Budapest, Hungary

8 Catalan Institute of Oncology (ICO), Barcelona, Spain

9 Bellvitge Biomedical Research Institute (IDIBELL), Barcelona, Spain

10 Cancer Prevention Unit and WHO Collaborating Centre for Tobacco Control, German Cancer Research Center (DKFZ), Heidelberg, Germany

11 University of Medicine and Pharmacy 'Grigore T.

Popa' lasi, lasi, Romania

12 Aer Pur Romania, Bucharest, Romania

13 European Observatory of Health Inequalities,

President Stanisław Wojciechowski State University of Applied Sciences, Kalisz, Poland

14 Department of Psychology and School of Public Health and Health Systems, University of Waterloo (UW), Waterloo, Canada

15 Ontario Institute for Cancer Research, Toronto, Canada

16 European Network for Smoking and Tobacco

Prevention (ENSP), Brussels, Belgium

17 University of Crete (UoC), Heraklion, Greece

\section{CORRESPONDENCE TO}

Katherine A. East. National Addiction Centre, Institute of Psychiatry, Psychology and Neuroscience, King's College London, 4 Windsor Walk, London SE5 8BB, United Kingdom. E-mail: katherine.east@kcl.ac.uk ORCID ID: https://orcid.org/0000-0001-9083-2131

\section{KEYWORDS}

survey, smoking, Europe, electronic cigarettes, social norms

Received: 23 November 2018

Revised: 16 January 2019

Accepted: 14 February 2019 


\section{INTRODUCTION}

Tobacco smoking is the leading cause of preventable morbidity and mortality worldwide ${ }^{1,2}$. In the European Union (EU), just over a quarter of adults $(26 \%)$ reported currently smoking tobacco in $2017^{3}$. However, the nicotine market has changed since the relatively recent introduction of electronic cigarettes (e-cigarettes $)^{4}$, and there has been a rapid increase in their awareness and use in some countries ${ }^{5-7}$. Both combustible tobacco cigarettes and most e-cigarette liquids contain nicotine, the addictive component of smoking. While not entirely absolved from health risks, some reports suggest that e-cigarette use is less harmful than tobacco smoking to both users and people around them, since e-cigarettes do not contain tobacco and do not involve combustion ${ }^{8-10}$. In $2017,2 \%$ of the EU population reported current e-cigarette use $\mathrm{e}^{3}$.

Social norms towards smoking are often identified as important sources of influence for smoking initiation $^{11-13}$, intention to quit smoking ${ }^{14-16}$, and smoking cessation ${ }^{14-16}$. In the smoking literature, social norms are commonly defined as perceived approval of smoking by friends, family, those important to them,

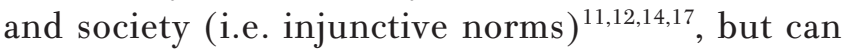
also include indicators of perceived visibility, such as self-reported friend smoking and perceptions of how common smoking is (i.e. descriptive norms) ${ }^{13,18,19}$. E-cigarettes, by comparison, are a relatively new product and there is less research on the social norms surrounding them. There have been some debated concerns expressed in the literature $\mathrm{e}^{20-22}$ and the EU Tobacco Products Directive (TPD) 2014 report $^{23}$ that e-cigarettes might 'renormalise' smoking and promote tobacco consumption. Given this, research evaluating social norms towards both e-cigarettes and smoking is of particular importance in the EU.

It is possible that individuals from countries with higher smoking prevalence rates have more pro-smoking social norms. A study among adult smokers in 2002-2003 found that perceived social denormalisation of smoking was lowest in the UK compared with Canada, Australia, and the $\mathrm{US}^{14}$; during these years the UK had the highest prevalence of any tobacco smoking of these four countries ${ }^{24}$. Further, a study assessing the 27 countries of the EU found that attitudes towards smoking restrictions were more favourable among those countries with more advanced tobacco control policies and lower smoking prevalence rates $^{25}$. Less is known about country differences in social norms towards e-cigarettes.

Figure 1 shows the prevalence of smoking and e-cigarette use in the seven EU countries of the EUREST-PLUS and International Tobacco Control Policy Evaluation (ITC) Project: Romania, Spain, Hungary, Poland, Greece, Germany, and England. An overview of each country's tobacco and e-cigarette policy environment is also provided (Figure 1). Of these countries, England had the lowest rates of current smoking (17\%) in $2017^{3}$, accompanied by a strong history of tobacco control policies (Figure 1). Germany, Romania, Spain, Hungary, and Poland have similar rates of current smoking (25-30\%), while Greece has the highest current smoking rate (37\%) (Figure 1). E-cigarette prevalence rates and policies also differ across these countries (Figure 1); however, any, rather than current, e-cigarette use is described, due to low rates of current e-cigarette use and few country differences ${ }^{3}$. England has the highest rates of any e-cigarette use (21\%), while Poland, Greece, and Germany (14-15\%), and Romania, Spain, and Hungary (10-12\%) have similar rates (Figure 1).

The objective of this study was to explore whether social norms towards smoking and e-cigarettes among adult smokers align with smoking and e-cigarette prevalence rates in the seven EU countries of the EUREST-PLUS and ITC Project. It was hypothesised that: 1) social norms will be more pro-smoking among smokers from countries with higher rates of current smoking (i.e. Greece), compared to those from countries with lower rates of current smoking (i.e. England); and 2) social norms will be more pro-ecigarette among smokers from countries with higher rates of any e-cigarette use (i.e. England), compared to those from countries with lower rates of any e-cigarette use (i.e. Hungary, Romania, Spain).

\section{METHODS}

\section{Pre-registration}

The hypotheses, methods and analysis plan were preregistered on the Open Science Framework on 10 May $2018^{26}$. Hypothesis 2 was changed slightly due to a mistake in the analysis pre-registration, whereby Romania was initially missed.

\section{Sample}

This study is part of the European Regulatory Science 
Figure 1. Key tobacco and e cigarette policies in England, Romania, Spain, Hungary, Poland, Greece, and Germany ${ }^{3,23,27,28}$

\begin{tabular}{|c|c|c|c|c|c|c|c|c|c|c|c|c|}
\hline & \multirow{2}{*}{$\begin{array}{l}\text { Smoke-free (SF) } \\
\text { legislation }\end{array}$} & \multirow{2}{*}{$\begin{array}{l}\text { Health warnings } \\
(\mathrm{HWs})+\text { packaging }\end{array}$} & \multirow{2}{*}{$\begin{array}{l}\text { Advertising, promotion + } \\
\text { sponsorship, including Point of } \\
\text { Sale (PoS) }\end{array}$} & \multirow{2}{*}{$\begin{array}{l}\text { Tax } \\
\text { (average retail } \\
\text { pack price' }^{\text {in }} \\
\text { 2016) }\end{array}$} & \multirow{2}{*}{$\begin{array}{l}\text { National } \\
\text { campaign } \\
\text { 2014- } \\
\text { 2016? }\end{array}$} & \multirow{2}{*}{$\begin{array}{c}\text { Year } \\
\text { vending } \\
\text { machine } \\
\text { sales } \\
\text { banned }\end{array}$} & \multirow{2}{*}{$\begin{array}{l}\text { Other tobacco control } \\
\text { policies }\end{array}$} & \multirow{2}{*}{$\begin{array}{l}\text { E-cigarette policies } \\
\text { as of } 2016\end{array}$} & \multirow{2}{*}{$\begin{array}{l}\text { Year } \\
\text { ratified } \\
\text { FCTC }^{2}\end{array}$} & \multirow{2}{*}{$\begin{array}{l}2016 \\
\text { TCS }^{3} \\
\text { score }\end{array}$} & \multicolumn{2}{|c|}{$\begin{array}{l}2017 \text { prevalence } \\
\text { among adults }\end{array}$} \\
\hline & & & & & & & & & & & $\begin{array}{l}\text { Current } \\
\text { smoking }\end{array}$ & $\begin{array}{c}\text { Any } \\
\mathrm{EC}\end{array}$ \\
\hline England & $\begin{array}{l}\text { 2007: Comprehensive, } \\
\text { compliance good. Hotel } \\
\text { rooms, prisons, + } \\
\text { nursing homes excepted. }\end{array}$ & $\begin{array}{l}\text { 2009: HWs } 40 \% \text { of } \\
\text { back. 2016: Plain } \\
\text { packaging. }\end{array}$ & $\begin{array}{l}\text { 2003: Partial ban. 2004: PoS } \\
\text { regulation. 2005: International } \\
\text { sponsorship ban. 2010: Ban TV } \\
\text { product placement. 2012-2015: } \\
\text { Comprehensive ban, including } \\
\text { PoS. }\end{array}$ & $\begin{array}{c}\text { 2002: } 78 \% \\
\text { 2011-2014: } \\
\text { Increase by 2\% } \\
\text { above inflation. } \\
\text { (€9.42) }\end{array}$ & Yes & 2011 & $\begin{array}{l}\text { 2015: Ban smoking in } \\
\text { private vehicles with } \\
\text { children }<18 \text {. }\end{array}$ & & 2004 & $\begin{array}{l}81 \\
\text { (UK) }\end{array}$ & $17 \%(U K)$ & $\begin{array}{l}21 \% \\
\text { (UK) }\end{array}$ \\
\hline Romania & $\begin{array}{l}\text { 2008: Partial, allowances } \\
\text { for designated smoking } \\
\text { areas. 2016: } \\
\text { Comprehensive. }\end{array}$ & $\begin{array}{l}\text { 2008: HWs } 230 \% \text { of } \\
\text { pack, characteristics + } \\
\text { position specified, } \\
\text { banned packs }<20 .\end{array}$ & $\begin{array}{l}\text { 2008: Comprehensive ban except } \\
\text { PoS. }\end{array}$ & $\begin{array}{l}\text { 2014: } 75 \% \\
\text { (€3.28) }\end{array}$ & Yes & 2008 & & $€ 0.11$ tax per ml. & 2006 & 56 & $28 \%$ & $11 \%$ \\
\hline Spain & $\begin{array}{l}\text { 2006: Comprehensive } \\
\text { except designated } \\
\text { smoking rooms. }\end{array}$ & $\begin{array}{l}\text { 2002: HWs } 230 \% \\
\text { front, } 10 \% \text { sides, } \\
\text { rotated, constituents } \\
\text { listed. 2006: Banned } \\
\text { packs } 20.2010 \text {. } \\
\text { Pictorial HWs. }\end{array}$ & $\begin{array}{l}\text { 2003: Comprehensive ban. 2006: } \\
\text { Smoking + product placement in } \\
\text { media banned. No PoS ban. }\end{array}$ & $\begin{array}{c}\text { 2014: } 78 \% \\
\text { (€4.44) }\end{array}$ & No & $\begin{array}{c}\text { Not } \\
\text { banned }\end{array}$ & $\begin{array}{l}\text { 2003: Misleading } \\
\text { descriptors banned. 2006: } \\
\text { Discounts prohibited. }\end{array}$ & $\begin{array}{l}\text { Banned where } \\
\text { smoking is banned. } \\
\text { Advertisements } \\
\text { regulated. }\end{array}$ & 2005 & 55 & $28 \%$ & $12 \%$ \\
\hline Hungary & $\begin{array}{l}\text { 1999: Comprehensive } \\
\text { except designated } \\
\text { smoking areas. }\end{array}$ & $\begin{array}{l}\text { 1999: HWs } 30 \% \text { front, } \\
40 \% \text { back, } 10 \% \text { sides, } \\
\text { rotated. }\end{array}$ & $\begin{array}{l}\text { 1995: Comprehensive advertising } \\
\text { ban. 2008: Promotion + } \\
\text { sponsorship banned, except PoS. }\end{array}$ & $\begin{array}{c}\text { 2014: } 77 \% \\
(€ 3.38)\end{array}$ & No & 2006 & $\begin{array}{l}\text { 1999: Tobacco sold } \\
\text { separate from unrelated } \\
\text { products. 2011: } \\
\text { Misleading descriptors } \\
\text { banned. 2014: Sale only in } \\
\text { National Tobacco Shops. }\end{array}$ & $\begin{array}{l}\text { €0.21 tax per ml. } \\
\text { Advertising banned. } \\
\text { Banned where } \\
\text { smoking is banned. } \\
\text { Flavours prohibited. }\end{array}$ & 2004 & 53 & $27 \%$ & $10 \%$ \\
\hline Poland & $\begin{array}{l}\text { 2010: Partial, exceptions } \\
\text { e.g. drinking/eating } \\
\text { establishments with }>2 \\
\text { rooms. }\end{array}$ & $\begin{array}{l}\text { 2004: HWs on packs + } \\
\text { point of sale (PoS). }\end{array}$ & $\begin{array}{l}\text { 1996: Comprehensive ban, except } \\
\text { PoS. }\end{array}$ & $\begin{array}{c}2014: 80 \% \\
\text { (€3.13) }\end{array}$ & Yes & 1996 & $\begin{array}{l}\text { 1996: Additives which } \\
\text { increase risk of addiction } \\
\text { banned. }\end{array}$ & $\begin{array}{l}\text { Advertising ban. } \\
\text { Banned where } \\
\text { smoking is banned. }\end{array}$ & 2006 & 50 & $30 \%$ & $15 \%$ \\
\hline Greece & $\begin{array}{l}\text { 2009: Comprehensive, } \\
\text { compliance problematic. }\end{array}$ & & $\begin{array}{l}\text { 2005: Comprehensive advertising } \\
\text { ban. 2008: Banned sale and } \\
\text { advertising in health and } \\
\text { educational facilities. No PoS ban. }\end{array}$ & $\begin{array}{c}2014: 80 \% \\
(€ 3.71)\end{array}$ & No & 2009 & $\begin{array}{l}\text { 2008: Prohibited } \\
\text { manufacture of items } \\
\text { resembling tobacco } \\
\text { products. }\end{array}$ & $\begin{array}{l}\text { Banned wherever } \\
\text { smoking is banned. }\end{array}$ & 2006 & 40 & $37 \%$ & $15 \%$ \\
\hline Germany & $\begin{array}{l}\text { 2007: State-level. 2008: } \\
\text { All states SF restaurants, } \\
\text { bars + pubs, with } \\
\text { exceptions. } 2010 \\
\text { onwwards: } \\
\text { Comprehensive in } 3 \text { of } \\
16 \text { states. }\end{array}$ & $\begin{array}{l}\text { 2002: HWs } \geq 30 \% \text { of } \\
\text { pack, another HW } \\
\geq 40 \% \text { of another } \\
\text { surface. One of two } \\
\text { HWs required. }\end{array}$ & $\begin{array}{l}\text { 2003: Advertising + sponsorship } \\
\text { banned. 2010: Promotion } \\
\text { banned. 2016: Only EU country } \\
\text { allowing advertising on billboards. } \\
\text { No PoS ban. }\end{array}$ & $\begin{array}{l}2014: 73 \% \\
\quad(€ 5.34)\end{array}$ & Yes & $\begin{array}{c}\text { Not } \\
\text { banned }\end{array}$ & $\begin{array}{l}\text { 2002: Misleading } \\
\text { descriptors banned. }\end{array}$ & & 2004 & 37 & $25 \%$ & $14 \%$ \\
\hline $\begin{array}{c}\text { ALL } \\
\left(E \cup T P D^{4}\right)\end{array}$ & & $\begin{array}{l}\text { 2016: HWs } \geq 65 \% \\
\text { front and back, text + } \\
\text { picture + cessation } \\
\text { info, rotated per } \\
\text { annum, restricted } \\
\text { pack size. }\end{array}$ & & & & & $\begin{array}{l}\text { 2016: Characterising } \\
\text { flavours and misleading } \\
\text { descriptors banned, } \\
\text { internet sales banned. }\end{array}$ & $\begin{array}{l}\text { 2016: } 20 \mathrm{mg} / \mathrm{mL} \\
\text { nicotine limit, } \mathrm{HWs} \\
30 \% \text { of front } \& \text { back, } \\
\text { comprehensive } \\
\text { advertising, } \\
\text { promotion }+ \\
\text { sponsorship ban. }\end{array}$ & & & & \\
\hline
\end{tabular}

1 Average retail pack price for most popular brand in 2016. 2 FCTC: Framework Convention on Tobacco Control. 3 TCS: Tobacco Control Scale; higher scores indicate stronger implementation of tobacco control policies. 4 EU TPD: European Union Tobacco Products Directive; however there was a 1 year implementation period for these policies, and not all were in place for all countries at the time of surveying.

on Tobacco: Policy Implementation to Reduce Lung Disease (EUREST-PLUS) Project ${ }^{29,30}$. Data were drawn from Wave 1 of the ITC Six European Country (6E1) Survey (Romania, Spain, Hungary, Poland, Greece, Germany; approximately $n=1000$ per country) and the England arm of the Wave 1 ITC Four Country Smoking and Vaping (4CV1) Survey $(n=3536)$. These surveys were designed to be nationally representative of current cigarette smokers aged $\geq 18$ years in each country. Survey weights were incorporated to enhance representativeness, and were calculated using information on gender, age, urbanization, and region from national benchmark surveys; further details are provided elsewhere ${ }^{29-32}$.

Data from the ITC 6E1 Survey were collected between 18 June and 12 September 2016. Briefly, data were collected via face-to-face household interviews using tablets (CAPI) and respondents were sampled using a probability approach. Approximately 100 area clusters were sampled in each country, with the aim of obtaining 10 adult smokers per cluster. Within each cluster, household addresses were sampled using a random walk design, and where possible one randomly selected male smoker and one randomly selected female smoker were chosen for interview. Monetary incentives were provided to respondents based on each survey agency's remuneration structure (Germany, Hungary, Poland $€ 10$; Romania $€ 7$; Greece $€ 5$; Spain $€ 3$ ). Further details are available elsewhere $^{29-31}$.

Data from the ITC 4CV1 England Survey were collected between 7 July and 16 November 2016 . Briefly, data were collected online and the majority of respondents were sampled using a non-probability 
approach. The sample comprised the following cohorts: 1) recontact smokers and quitters living in England who participated in Wave 10 of the earlier 4 Country (4C) Project in the UK; 2) newly recruited current smokers and recent quitters (quit in past 24 months) from a commercial online panel; and 3) newly recruited current e-cigarette users (use at least weekly) from a commercial online panel. In sampling, quotas obtained from national survey data for region crossed with male/female were applied to 2) and 3). Respondents were recruited via random-digit-dialling (RDD) sampling frames, or web-based or addressbased panels, or a combination of these frames. Incentives were provided to respondents either in the form of a $£ 16$ e-gift card or survey panellist points worth $£ 16-£ 20$. Further details are available elsewhere $^{32}$. Only data from adult current cigarette smokers were used for this study.

\section{Measures}

\section{Social norms (outcomes)}

The wording of some measures differed between countries. Where wording differed, both measures from the English-translated European Country Surveys $^{33}$, and the England arm of the 4CV1 Survey ${ }^{34}$ are listed separately below. For all social-norms measures, 'Refused' and 'Don't know' responses were coded as missing and multiple imputation was used (see Analyses section).

(i) At least three of five closest friends smoke. European Survey: 'Of the five closest friends or acquaintances that you spend time with on a regular basis... How many of them smoke ordinary cigarettes? 0-5'. England Survey: 'How many friends or acquaintances do you spend time with on a regular basis? 0-5, More than 5', followed by 'Of (these $1-5 /$ the 5 closest) friends or acquaintances that you spend time with on a regular basis, how many of them smoke ordinary cigarettes? $0-5$ '. Responses were dichotomised as less than three $(0-2)$ vs at least three (3-5).

(ii) People important to you approve of smoking. 'What do people who are important to you think about you smoking cigarettes? (a) All or nearly all approve, (b) Most approve, (c) About half approve and half disapprove, (d) Most disapprove, (e) All or nearly all disapprove'. Responses were dichotomised as 'approve' (a-b) or 'not approve' (c-e). (iii) The public approves of smoking. What do you think the general public's attitude is towards smoking cigarettes? (a) Strongly approves, (b) Somewhat approves, (c) Neither approves nor disapproves, (d) Somewhat disapproves, (e) Strongly disapproves'. Responses were dichotomised as 'approve' (a-b) or 'not approve' (c-e).

(iv) People who smoke are marginalised. 'People who smoke are more and more marginalized. (a) Strongly agree, (b) Agree, (c) Neither agree nor disagree, (d) Disagree, (e) Strongly disagree'. Responses were dichotomised as 'disagree' (d-e) or 'not disagree' (a-c).

(v) At least one of five closest friends use e-cigarettes. European Survey: 'Of the five closest friends or acquaintances that you spend time with on a regular basis... How many of them use e-cigarettes or vaping devices? 0-5'. England Survey: 'How many friends or acquaintances do you spend time with on a regular basis? 0-5, More than 5', followed by 'Of [these 1-5 / the 5 closest] friends or acquaintances that you spend time with on a regular basis, how many of them use e-cigarettes / vaping devices? 0-5'. Responses were dichotomised as none (0) or at least one (1-5), due to the low percentage of respondents who had friends using e-cigarettes.

(vi) The public approves of e-cigarettes. European Survey: 'What do you think the general public's attitude is towards using e-cigarettes or vaping devices?' England Survey: 'What do you think the general public's attitude is towards vaping/ using e-cigarettes? (a) Strongly approves, (b) Somewhat approves, (c) Neither approves nor disapproves, (d) Somewhat disapproves, (e) Strongly disapproves'. Responses were dichotomised as 'approve' (a-b) or 'not approve' (c-e).

(vii) Seeing e-cigarette use in public. European Survey: 'In the last 30 days, how often have you seen anyone using an e-cigarette or vaping device in public?' England Survey: 'In the last 30 days, how often, if at all, have you seen anyone vaping (using e-cigarettes) in public? (a) Every day, (b) Most days, (c) Some days, (d) Rarely, (e) Not at all'. Responses were dichotomised as 'at least some days' (a-c), or 'rarely/not at all' (d-e).

\section{Country}

Country was the key correlate: England, Romania, Spain, Hungary, Poland, Greece, Germany. 


\section{Covariates}

Age: 18-24, 25-39, 40-54, $\geq 55$.

Sex: male, female.

Household income: low, moderate, high, not reported.

For England (£) based on annual income: low $\leq 15000$, moderate 15001-30000, high $>30000$. For the other countries based on monthly income. Germany, Greece and Spain $(€)$ : low $<1750$, moderate 1750-3000, high $>3000$. For Hungary (Ft): low $\leq 150000$, moderate 150001-250000, high >250000. For Poland (zt): low $\leq 2000$, moderate 2001-4000, high $>4000$. For Romania (lei): low $\leq 1000$, moderate 1001-2500, high $>2500$.

Education: low, moderate, high.

This variable was defined using the International Standard Classification of Education (ISCED), which was, in turn, categorised into low (pre-primary, primary, lower secondary), moderate (upper secondary, post-secondary non-tertiary, short-cycle tertiary), and high (bachelor or equivalent, master or equivalent, doctoral or equivalent).

Smoking status: daily, non-daily.

E-cigarette status: current user (use daily, weekly, or occasionally), current non-user.

Heaviness of Smoking Index (HSI): 0-6.

The HSI consists of two items: time to first cigarette after waking and number of cigarettes per day ${ }^{35}$. Responses to each item were allocated a score between 0 and 3 , and these scores were summed, such that higher values indicate greater heaviness of smoking.

\section{Analyses}

Analyses were conducted using Stata v $15^{36}$. First, the percentages of each social-norms outcome (i-vii) were calculated overall and per country. Second, seven unadjusted and adjusted logistic regression models were used to assess associations between country and each social-norms outcome (i-vii). Adjusted models included all covariates listed above. Stata's svy command was used for all analyses to account for complex samples design, incorporating survey weights and strata. All frequencies (n) use unweighted, unstratified, 'raw' data; all percentages (\%) use weighted, stratified data.

\section{Missing data}

Of the initial 9547 respondents, those who had never heard of e-cigarettes $(n=1757)$ or selected 'Don't know' $(n=11)$ when asked about their e-cigarette status were excluded listwise, leaving 7779 respondents. Missing data were not Missing Completely at Random (MCAR), as country, age, sex, income, education, HSI and e-cigarette use were all associated with missingness. Multiple imputation was therefore used on the remaining sample $(n=7779)$ under the Missing at Random (MAR) assumption for the following 'Don't know' and 'Refused' responses: friend smoking ( $\mathrm{n}=721$ [9.3\%] observations imputed), people important to you approve of smoking $(n=415$ [5.3\%]), public approve of smoking $(n=222[2.9 \%])$, people who smoke are marginalised $(n=288[3.7 \%])$, friend e-cigarette use $(n=773[9.9 \%])$, public approve of e-cigarettes $(n=969[12.5 \%])$, seeing e-cigarette use in public $(n=211[2.7 \%])$, education $(n=90$ [1.2\%]). Multiple imputation was also used on HSI $(n=609$ [7.8\%] observations imputed); this deviated from the pre-registration ${ }^{26}$ due to unanticipated missing values on HSI.

Missing values were imputed using chained equations, and one model was used specifying imputation via logistic regression for all socialnorms measures, linear regression for HSI, and ordinal logistic regression for education. Country, age, sex, income, smoking status, and e-cigarette status were included as predictors in the model, and survey weights and strata were incorporated. Forty imputations were used because $31 \%$ of respondents had missing data (i.e. responded 'Don't know' or 'Refused') on at least one variable included in this study $^{26}$. More respondents from the England sample, who completed the survey online, had missing data on at least one variable (43\%) than those from the European samples who completed the survey face-toface $(21 \%)$. Sensitivity analyses found no differences in the prevalence of any social-norms measure $\pm 1 \%$, in the direction of any odds ratios, or in the significance indicated by p-values at the 0.05 cut-off, when using multiple imputation vs complete case analysis.

\section{RESULTS}

\section{Sample characteristics}

Most respondents were aged 40-54 years, male, had moderate income except Germany (most low or moderate) and England (most high), had moderate education except Germany and Hungary (both majority low education), and were daily smokers but not current e-cigarette users (Table 1). 
Table 1. Sample characteristics by country, all \% (n) except Heaviness of Smoking Index (HSI), which is mean (SD)

\begin{tabular}{|c|c|c|c|c|c|c|c|c|}
\hline & $\begin{array}{l}\text { England } \\
\text { (n-3518) }\end{array}$ & $\begin{array}{l}\text { Romania } \\
(\text { (n- 679) }\end{array}$ & $\begin{array}{l}\text { Spain } \\
(n-851)\end{array}$ & $\begin{array}{l}\text { Hungary } \\
\text { (n - 681) }\end{array}$ & $\begin{array}{l}\text { Poland } \\
\text { (n-677) }\end{array}$ & $\begin{array}{l}\text { Grecee } \\
(n-737)\end{array}$ & $\begin{array}{l}\text { Germany } \\
(n-636)\end{array}$ & $\begin{array}{c}\text { Total } \\
(\text { (n } 7779)\end{array}$ \\
\hline \multicolumn{9}{|l|}{ Age } \\
\hline $18-24$ & 16.7 (798) & $15.3(82)$ & 12.9 (106) & $9.7(41)$ & $7.4(48)$ & $9.6(51)$ & $9.7(64)$ & 15.3 (1190) \\
\hline $25-39$ & $32.3(864)$ & 39.1 (210) & $29.6(266)$ & $35.8(202)$ & 36.1 (249) & 30.8 (209) & $24.3(173)$ & 27.9 (2173) \\
\hline $40-54$ & 26.4 (936) & 30.5 (217) & 39.7 (287) & $33.4(242)$ & 30.2 (189) & 34.5 (285) & 37.3 (217) & 30.5 (2373) \\
\hline$\geq 55$ & 24.7 (920) & $15.1(170)$ & 17.8 (192) & $21.2(196)$ & $26.3(191)$ & 25.0 (192) & 28.7 (182) & 26.3 (2043) \\
\hline Female & 45.9 (1573) & $41.0(272)$ & 43.5 (394) & 40.4 (324) & $44.6(366)$ & 47.0 (344) & 38.7 (313) & 46.1 (3586) \\
\hline \multicolumn{9}{|l|}{ Income } \\
\hline Low & $22.4(771)$ & 15.4 (129) & $25.5(225)$ & 15.4 (117) & $13.2(106)$ & $16.5(117)$ & $29.8(191)$ & $21.3(1656)$ \\
\hline Moderate & $29.8(1024)$ & $44.1(311)$ & $29.7(241)$ & 27.8 (194) & 33.7 (233) & 56.8 (398) & $29.3(200)$ & $33.4(2601)$ \\
\hline High & $38.4(1435)$ & 32.9 (182) & $6.4(63)$ & $25.6(165)$ & 17.7 (112) & $10.4(83)$ & $25.5(16)$ & 28.4 (2205) \\
\hline Not reported & $9.4(288)$ & 7.6 (57) & $38.4(322)$ & $31.2(205)$ & 35.5 (226) & 16.4 (139) & $15.4(80)$ & 16.9 (1317) \\
\hline \multicolumn{9}{|l|}{ Education $^{\mathrm{a}}$} \\
\hline Low & $20.2(1002)$ & 23.5 (160) & $43.3(342)$ & 61.5 (394) & $12.6(89)$ & $28.3(201)$ & $50.3(323)$ & 32.5 (2511) \\
\hline Moderate & 66.2 (1399) & $64.4(436)$ & $48.3(432)$ & 31.6 (234) & 75.2 (492) & 49.9 (368) & 40.8 (259) & $47.3(3620)$ \\
\hline High & $13.7(1051)$ & $12.1(75)$ & $8.4(76)$ & $6.9(51)$ & $12.2(86)$ & $21.9(167)$ & $8.9(52)$ & 20.2 (1558) \\
\hline Daily smoker & $83.3(2866)$ & $96.0(649)$ & $97.6(827)$ & $98.9(673)$ & 96.6 (647) & $96.6(711)$ & 90.9 (578) & 89.4 (6951) \\
\hline Current EC user & 42.6 (1857) & $4.8(25)$ & $1.3(10)$ & $3.6(22)$ & $3.5(25)$ & $5.4(41)$ & $9.1(54)$ & 26.2 (2034) \\
\hline $\mathrm{HSI}^{\mathrm{a}}$ & $2.0(0.0)$ & $2.9(0.1)$ & $2.3(0.1)$ & $2.9(0.1)$ & $2.6(0.1)$ & $2.9(0.1)$ & $2.2(0.1)$ & $2.3(0.0)$ \\
\hline
\end{tabular}

Percentages (\%) are weighted and stratified using multiply imputed data. Frequencies (n) are unweighted and unstratified, without multiple imputation. a Missing data on education $(n=90,1.2 \%)$ and HSI $(n=609,7.8 \%)$. EC: e-cigarette, HIS: Heaviness of Smoking Index.

\section{Prevalence of each social-norms measure}

Overall, $50 \%$ of respondents reported that at least three of their five closest friends smoke, $21 \%$ perceived that people important to them approve of smoking, $13 \%$ perceived that the public approves of smoking, and $19 \%$ disagreed that people who smoke are marginalised (Table 2). Overall, $24 \%$ of respondents reported that at least one of their five closest friends uses e-cigarettes, $32 \%$ perceive that the public approve of e-cigarettes, and $81 \%$ reported seeing e-cigarette use in public at least some days (Table 3 ). There was substantial difference between countries in smoking (Table 2) and e-cigarette (Table 3) norms; these are examined in further detail below.

\section{Hypothesis 1. Social norms towards smoking} will be higher in countries with greater current smoking rates

(i) Reporting that at least three of five closest friends smoke

Both unadjusted and adjusted odds of reporting that at least three of five closest friends smoke were highest in Greece, followed by Romania, Spain, Germany,
Poland, Hungary, and lowest in England (Table 2). Odds were 6 to 24 times higher in all countries compared with England, and the results also suggest odds were higher in Greece than all countries except Romania, and in Romania than Poland, Hungary, and Germany (Table 2).

(ii) Perceiving that people important to you approve of smoking

Both unadjusted and adjusted odds of perceiving that people important to you approve of smoking were highest in Hungary, followed by Germany, Romania/ Poland, Greece, Spain, and lowest in England (Table 2). Odds were 1.8 to 16 times higher in all countries compared with England, and the results also suggest odds were higher in Hungary and Germany than all other countries, and in Poland and Romania than Spain (Table 2).

\section{(iii) Perceiving that the public approves of smoking.}

Unadjusted odds of perceiving that the public approves of smoking were highest in Hungary, followed by Romania, Germany, Poland, Greece, 
Table 2. Adjusted associations between each social norm towards smoking measures (i)-(iv) and country ( $\mathrm{N}=7779)$

\begin{tabular}{|c|c|c|c|c|c|c|c|c|c|}
\hline & \multicolumn{2}{|c|}{$\begin{array}{l}\text { (i) Al least three of } \\
\text { five closest friends } \\
\text { smoke }\end{array}$} & \multicolumn{2}{|c|}{$\begin{array}{c}\text { (ii) People important } \\
\text { to you approve of } \\
\text { smoking }\end{array}$} & \multicolumn{2}{|c|}{$\begin{array}{l}\text { (iii) The public } \\
\text { approves of } \\
\text { smoking }\end{array}$} & \multicolumn{2}{|c|}{$\begin{array}{l}\text { (iv) Disagree that } \\
\text { people who smoke } \\
\text { are marginalised }\end{array}$} & \multirow{2}{*}{$\begin{array}{c}\text { Current } \\
\text { smoking } \\
\text { in } 2017^{a} \\
\left({ }^{\circ}\right)\end{array}$} \\
\hline & $\%$ & OR $\left(95^{\circ} \circ \mathrm{CI}\right)$ & $\%$ & OR $\left(95^{\circ} \% \mathrm{CI}\right)$ & $\%$ & OR $\left(95^{\circ} \circ \mathrm{CI}\right)$ & $\%$ & OR $\left(95^{\circ} \circ \mathrm{CI}\right)$ & \\
\hline \multicolumn{10}{|c|}{ England ( $n=3518$; ref) } \\
\hline & 19.4 & 1.00 & 7.7 & 1.00 & 4.9 & 1.00 & 9.1 & 1.00 & 17 \\
\hline \multicolumn{10}{|l|}{ Greece $(n=737)$} \\
\hline Unadjusted & 83.7 & 21.38 (16.74-27.32) & 18.9 & $2.77(2.09-3.69)$ & 16.0 & $3.73(2.72-5.12)$ & 50.2 & $10.11(8.03-12.73)$ & 37 \\
\hline Adjusted & & $23.98(18.25-31.50)$ & & $2.84(2.07-3.91)$ & & $5.19(3.61-7.46)$ & & 12.25 (9.39-15.97) & \\
\hline \multicolumn{10}{|l|}{ Poland $(n=677)$} \\
\hline Unadjusted & 69.8 & 9.59 (7.67-12.00) & 25.9 & $4.17(3.20-5.43)$ & 19.1 & $4.63(3.42-6.25)$ & 16.5 & $1.99(1.48-2.67)$ & 30 \\
\hline Adjusted & & 10.55 (8.14-13.67) & & $4.62(3.40-6.27)$ & & $6.82(4.77-9.75)$ & & $2.34(1.69-3.24)$ & \\
\hline \multicolumn{10}{|c|}{ Romania ( $n=679)$} \\
\hline Unadjusted & 82.8 & 20.01 (15.55-25.75) & 28.6 & $4.79(3.67-6.25)$ & 21.0 & $5.19(3.78-7.12)$ & 38.6 & $6.32(4.96-8.05)$ & 28 \\
\hline Adjusted & & $19.00(14.48-24.94)$ & & $4.44(3.30-5.98)$ & & $5.93(4.11-8.57)$ & & $6.90(5.24-9.09)$ & \\
\hline \multicolumn{10}{|l|}{ Spain $(n=851)$} \\
\hline Unadjusted & 73.5 & 11.53 (9.29-14.33) & 13.7 & $1.90(1.42-2.54)$ & 5.8 & $1.20(0.81-1.76)^{*}$ & 22.9 & $2.99(2.36-3.79)$ & 28 \\
\hline Adjusted & & $11.92(9.30-15.28)$ & & $1.86(1.34-2.58)$ & & $1.69(1.09-2.60)$ & & $3.35(2.54-4.42)$ & \\
\hline \multicolumn{10}{|l|}{ Hungary $(n=681)$} \\
\hline Unadjusted & 64.8 & $7.63(6.14-9.48)$ & 57.2 & $15.98(12.54-20.36)$ & 36.8 & 11.37 (8.67-14.89) & 10.6 & $1.19(0.83-1.71)^{*}$ & 27 \\
\hline Adjusted & & $6.88(5.37-8.82)$ & & $15.12(11.42-20.03)$ & & 15.80 (11.36-21.99) & & $1.36(0.94-1.97)^{*}$ & \\
\hline \multicolumn{10}{|c|}{ Germany ( $n=636)$} \\
\hline Unadjusted & 70.9 & 10.13 (8.08-12.70) & 54.9 & 14.51 (11.43-18.43) & 20.9 & $5.16(3.83-6.94)$ & 20.5 & 2.59 (1.99-3.37) & 25 \\
\hline Adjusted & & $11.13(8.69-14.26)$ & & $14.87(11.35-19.48)$ & & $6.59(4.71-9.21)$ & & $2.89(2.18-3.82)$ & \\
\hline Total $(n=7779)$ & 49.9 & & 21.1 & & 12.9 & & 19.0 & & \\
\hline
\end{tabular}

a Data on current smoking rates are from the 2017 Eurobarometer ${ }^{3}$. All data for (i)-(iv) are multiply imputed with survey weights and strata. OR: odds ratio. Adjusted values are adjusted for age, sex, income, education, smoking status, current e-cigarette use and heaviness of smoking index (HSI). *Data not significant at the $\mathrm{p} \leq 0.05$ cut-off.

Table 3. Adjusted associations between each social norm towards e cigarette measures (v)-(vii) and country ( $\mathrm{N}=7779)$

\begin{tabular}{|c|c|c|c|c|c|c|c|}
\hline & \multicolumn{2}{|c|}{$\begin{array}{l}\text { (v) At least one of five } \\
\text { closest friends uses } \\
\text { e cigarettes }\end{array}$} & \multicolumn{2}{|c|}{$\begin{array}{l}\text { (vi) The public approves } \\
\text { of e cigarettes }\end{array}$} & \multicolumn{2}{|c|}{$\begin{array}{c}\text { (vii) Seeing e cigarette } \\
\text { use in public at least some } \\
\text { days }\end{array}$} & \multirow{2}{*}{$\begin{array}{c}\text { Any e } \\
\text { cigarette use } \\
\text { in } 2017^{\mathrm{a}} \\
\left({ }^{\circ}\right)\end{array}$} \\
\hline & $\%$ & OR $\left(95^{\circ} \circ \mathrm{CI}\right)$ & $\%$ & OR $\left(95^{\circ} \circ \mathrm{CI}\right)$ & $\%$ & OR $\left(95^{\circ} \% \mathrm{CI}\right)$ & \\
\hline \multicolumn{8}{|c|}{ England ( $n=3518 ;$ ref) } \\
\hline & 28.0 & 1.00 & 31.8 & 1.00 & 80.5 & 1.00 & 21 \\
\hline \multicolumn{8}{|l|}{ Greece $(n=737)$} \\
\hline Unadjusted & 27.1 & $0.96(0.77-1.19)^{*}$ & 40.1 & $1.44(1.18-1.75)$ & 55.1 & $0.30(0.24-0.36)$ & 15 \\
\hline Adjusted & & 1.64 (1.27-2.11) & & $1.63(1.31-2.03)$ & & $0.39(0.31-0.49)$ & \\
\hline \multicolumn{8}{|l|}{ Poland $(n=677)$} \\
\hline Unadjusted & 35.6 & $1.42(1.14-1.76)$ & 35.9 & $1.20(0.97-1.49)^{*}$ & 44.6 & $0.20(0.16-0.24)$ & 15 \\
\hline Adjusted & & $2.69(2.06-3.50)$ & & 1.46 (1.14-1.85) & & $0.27(0.22-0.34)$ & \\
\hline \multicolumn{8}{|c|}{ Romania ( $n=679)$} \\
\hline Unadjusted & 13.5 & $0.49(0.30-0.54)$ & 26.1 & $0.76(0.59-0.97)$ & 29.5 & $0.10(0.08-0.13)$ & 11 \\
\hline Adjusted & & $0.64(0.47-0.88)$ & & $0.82(0.63-1.08)^{*}$ & & $0.12(0.09-0.15)$ & \\
\hline \multicolumn{8}{|l|}{ Spain $(n=851)$} \\
\hline Unadjusted & 5.7 & $0.15(0.11-0.21)$ & 23.7 & $0.67(0.53-0.84)$ & 12.7 & $0.04(0.03-0.05)$ & 12 \\
\hline Adjusted & & $0.31(0.22-0.44)$ & & $0.81(0.62-1.04)^{*}$ & & $0.05(0.04-0.07)$ & \\
\hline \multicolumn{8}{|l|}{ Hungary $(n=681)$} \\
\hline Unadjusted & 23.5 & $0.79(0.63-1.00)^{*}$ & 37.0 & $1.26(1.01-1.57)$ & 16.9 & $0.05(0.04-0.07)$ & 10 \\
\hline Adjusted & & $1.58(1.21-2.07)$ & & $1.49(1.17-1.89)$ & & $0.06(0.05-0.09)$ & \\
\hline \multicolumn{8}{|c|}{ Germany $(n=636)$} \\
\hline Unadjusted & 17.5 & $0.55(0.42-0.70)$ & 32.4 & $1.03(0.83-1.27)^{*}$ & 28.1 & $0.09(0.08-0.12)$ & 14 \\
\hline Adjusted & & $0.94(0.72-1.23)^{*}$ & & $1.22(0.97-1.53)^{*}$ & & $0.12(0.10-0.15)$ & \\
\hline Total $(n=7779)$ & 23.6 & & 32.1 & & 53.1 & & \\
\hline
\end{tabular}

a Data on any e-cigarette use are from the 2017 Eurobarometer $^{3}$. All data are multiply imputed with survey weights and strata. OR: odds ratio. Adjusted values are adjusted for age, sex, income, education, smoking status, current e-cigarette use and Heaviness of Smoking Index (HSI). *Data are not significant at the $\mathrm{p} \leq 0.05$ cut-off. 
Spain, and England, while adjusted odds were highest in Hungary, followed by Poland, Germany, Romania, Greece, Spain, and lowest in England (Table 2). The results suggest odds were lower in England and Spain compared with all other countries, higher in Hungary than all countries, and adjusted odds were also lower in England than Spain (Table 2).

(iv) Disagreeing that people who smoke are marginalised Both unadjusted and adjusted odds of disagreeing that people who smoke are marginalised were highest in Greece, followed by Romania, Spain, Germany, Poland, Hungary, and lowest in England (Table 2). The results suggest odds were lower in England and Hungary than all other countries, higher in Greece and Romania than all other countries, and adjusted odds were also higher in Greece than Romania (Table 2).

\section{Hypothesis 2. Social norms towards e-cigarettes will be higher in countries with greater rates of} any e-cigarette use

(v) Reporting that at least one of five closest friends uses e-cigarettes

Unadjusted odds of reporting that at least one of five closest friends uses e-cigarettes were highest in Poland, followed by England, Greece, Hungary, Germany, Romania, and lowest in Spain (Table 3). Adjusted odds were highest in Poland, followed by Greece, Hungary, England, Germany, Romania, and lowest in Spain (Table 3). The results suggest odds were generally higher in Poland compared with all countries except Greece, higher in Greece than Romania and Germany, higher in England and Hungary than Romania, and lower in Spain than all countries (Table 3).

(vi) Perceiving that the public approves of e-cigarettes Unadjusted and adjusted odds of perceiving that the public approves of e-cigarettes were highest in Greece, followed by Hungary, Poland, Germany, England, Romania, and lowest in Spain (Table 3). The results suggest odds were generally higher in Greece, Poland and Hungary than England, Romania, and Spain (Table 3).

(vii) Report seeing e-cigarette use in public at least some days

Unadjusted and adjusted odds of reporting seeing e-cigarette use in public at least some days was highest in England, followed by Greece, Poland, Romania, Germany, Hungary, and lowest in Spain (Table 3). Odds were 2.6 to 25 times higher in England compared with all countries, and the results also suggest higher odds in Greece and Poland than all other countries except England, and lower in Spain and Hungary than all other countries (Table 3 ).

\section{DISCUSSION}

Partially consistent with Hypothesis 1, smokers from countries with higher rates of current smoking generally had more pro-smoking social norms on two of four measures: reporting that at least three of their five closest friends smoke, and disagreeing that smokers are marginalised. Except England, generally perceived approval of smoking by those important to you and society did not align with country-level rates of current smoking. Somewhat consistent with Hypothesis 2, smokers from countries with higher rates of any e-cigarette use had more pro-e-cigarette social norms on one of three measures: seeing e-cigarette use in public at least some days. Generally, reporting that at least one of five closest friends uses e-cigarettes and perceiving that the public approves of e-cigarettes did not align with country-level rates of any e-cigarette use. Smokers from England had the least pro-smoking social norms across all four measures and countries, while those from Spain had the least pro-e-cigarette social norms across all three measures and countries.

The finding that England had the least pro-smoking norms across all four measures is unsurprising, given England's substantially lower smoking rate and long history of strong tobacco control policies compared with the other six EU countries in this study (Figure 1). However, England did not have the most pro-ecigarette social norms on two of three measures, despite its markedly higher country-level rates of any e-cigarette use compared with the other six countries (Figure 1) and some promotion of e-cigarettes as smoking cessation aids by UK public health bodies such as the NHS and Cancer Research UK.

The finding that smokers from Spain had the least pro-e-cigarette social norms across all three measures also warrants further exploration, given that prevalence of any e-cigarette use in Spain was not markedly different from any other country's except 
England. Public health authorities in Spain have generally applied precautionary principles towards e-cigarettes, such as banning their use in most public places and workplaces in 2014 (Figure 1). There has also been a delay in the general marketing of e-cigarettes in Spain compared with other countries. It should also be noted that Spanish smokers' low perceived approval of smoking, from those important to them (14\%) and the public (6\%), is not consistent with the higher smoking prevalence in Spain.

Averaged across all seven countries, perceived public approval of e-cigarettes $(32 \%)$ was over twice that of perceived public approval of smoking (13\%). Moreover, perceived public approval of e-cigarettes was also higher than that of smoking within all countries. This is consistent with reports suggesting e-cigarettes are less harmful to both users and people around them relative to combustible cigarettes ${ }^{8-10}$. It is not possible to compare the other social norms towards smoking with those social norms towards e-cigarettes due to different types of social norms being assessed.

This study is among the first in the EU to assess a variety of both descriptive, more 'visible' measures of adult smokers' social norms towards smoking and e-cigarettes, such as perceived friend use and seeing e-cigarette use in public, in addition to injunctive norms such as perceived approval. The results suggest that the injunctive norms measured here do not align with country-level rates of product use, nor do they generally correspond with the descriptive norms. Given literature highlighting the importance of measures of both the perceived visibility of smoking and perceived approval of smoking ${ }^{18}$, future research should aim to consider both normative domains.

There are several potential explanations as to why smokers' perceived approval of smoking by those important to them and that the public did not align with country-level current smoking rates as hypothesised. First, Hypothesis 1 was based on 2017 current smoking prevalence, which fails to consider each country's history of smoking prevalence, and current and previous tobacco control policies. These likely play important roles. Second, the sample was limited to current smokers, who are more likely to be of lower socioeconomic status and lacking the motivation and resources to quit ${ }^{37}$. Such individuals may hold more entrenched or polarised social norms; indeed, current smokers have been found to hold more pro-smoking norms across many selfreport measures compared to non-smokers and exsmokers ${ }^{19,38}$. Therefore, perceived approval of smoking among current smokers may be amplified in countries where they are in the minority, although this was not the case in England. Studies assessing smoking, and e-cigarette, social norms among non-smokers and exsmokers may aid interpretation of these findings.

The finding that social norms towards e-cigarettes, generally, did not align with country-level rates of any e-cigarette use as hypothesised could also be attributed to the sample containing current smokers only. In the EU, e-cigarettes are often used as an aid to smoking cessation ${ }^{3,39}$, and some smokers may be encouraged to switch from smoking to e-cigarette use due to the health benefits of switching over continued smoking ${ }^{7}$. Given this, it makes some sense that smokers from countries with historically higher rates of current smoking, such as Greece and Poland, would have greater adjusted odds of friend e-cigarette use and perceived public approval of e-cigarettes. However, this explanation is anecdotal and requires further research. Further, any e-cigarette use is a relatively weak measure of prevalence, yet options for a more refined comparator for Hypothesis 2 were limited, since prevalence of current e-cigarette use was low and similar for each country $(<1-5 \%)^{3}$. Current and previous e-cigarette policies were also not considered. Other potential explanations pertaining to the unanticipated results for both smoking and e-cigarette social norms include cross-country differences in culture, freedom of speech, liberty and social connectedness, which likely all play a role in the development of social norms ${ }^{40}$.

\section{Limitations and strengths}

This study is not without limitations. First, the results have limited generalizability since the sample contained only current smokers, who generally hold more pro-smoking norms across many self-report measures ${ }^{19,38}$, and have been found to perceive greater public approval of e-cigarettes ${ }^{19}$, compared to nonsmokers and ex-smokers. Second, the seven EU countries included in this study have all been working to reduce tobacco smoking through strengthening policies over the past decade, and all have some tobacco and e-cigarette policies harmonised under EU legislation. Inclusion of countries at an earlier stage 
of the tobacco epidemic or with considerably less restrictive tobacco control policies may have aided the interpretation of findings. Third, the English sample differed on the wording of some survey items, used online rather than face-to-face methodology, were offered greater monetary incentives, and had more missing data than the other EU country samples. This weakens comparisons made between England and the other countries. Fourth, smokers' understanding of these social-norms measures may differ across the different languages used, and may be subject to cultural biase ${ }^{41}$. Despite these limitations, this study is the first of its kind to compare social norms towards smoking and e-cigarettes in different EU countries, and uses large, nationally representative samples.

\section{CONCLUSIONS}

Among current smokers from seven EU countries, those from England had the least pro-smoking social norms, while those from Spain had the least pro-e-cigarette social norms. Reporting that at least three of five closest friends smoke and disagreeing that smokers are marginalised broadly aligned with country-level rates of current smoking, being lowest in England and highest in Greece. Seeing e-cigarette use in public broadly aligned with country-level any e-cigarette use, being lowest in Hungary, Romania and Spain, and highest in England. No other social norms were consistent with smoking and e-cigarette prevalence rates as hypothesised.

\section{*EUREST-PLUS consortium members:}

European Network on Smoking and Tobacco Prevention (ENSP), Belgium: Constantine I. Vardavas, Andrea Glahn, Christina N. Kyriakos, Dominick Nguyen, Katerina Nikitara, Cornel Radu-Loghin, Polina Starchenko University of Crete (UoC), Greece: Aristidis Tsatsakis, Charis Girvalaki, Chryssi Igoumenaki, Sophia Papadakis, Aikaterini Papathanasaki, Manolis Tzatzarakis, Alexander I. Vardavas

Kantar Public (TNS), Belgium: Nicolas Bécuwe, Lavinia Deaconu, Sophie Goudet, Christopher Hanley, Oscar Rivière

Smoking or Health Hungarian Foundation (SHHF), Hungary: Tibor Demjén, Judit Kiss, Piroska A. Kovács

Catalan Institut of Oncology (ICO); Bellvitge Biomedical Research Institute (IDIBELL), Spain: Esteve Fernández, Yolanda Castellano, Marcela Fu, Sarah 0. Nogueira, Olena Tigova

Kings College London (KCL), United Kingdom: Ann McNeill, Katherine East, Sara C. Hitchman

Cancer Prevention Unit and WHO Collaborating Centre for Tobacco Control, German Cancer Research Center (DKFZ), Germany: Ute Mons, Sarah Kahnert

National and Kapodistrian University of Athens (UoA), Greece: Yannis Tountas, Panagiotis Behrakis, Filippos T. Filippidis, Christina Gratziou, Paraskevi Katsaounou, Theodosia Peleki, Ioanna Petroulia, Chara Tzavara Aer Pur Romania, Romania: Antigona C. Trofor, Marius Eremia, Lucia Lotrean, Florin Mihaltan
European Respiratory Society (ERS), Switzerland; Goethe University Frankfurt, Germany: Gernot Rohde, Tamaki Asano, Claudia Cichon, Amy Far, Céline Genton, Melanie Jessner, Linnea Hedman, Christer Janson, Ann Lindberg, Beth Maguire, Sofia Ravara, Valérie Vaccaro, Brian Ward

Maastricht University, the Netherlands: Marc Willemsen, Hein de Vries, Karin Hummel, Gera E. Nagelhout

Health Promotion Foundation (HPF), Poland: Witold A. Zatoński, Aleksandra Herbeć, Kinga Janik-Koncewicz, Krzysztof Przewoźniak, Mateusz Zatoński University of Waterloo (UW); Ontario Institute for Cancer Research, Canada: Geoffrey T. Fong, Thomas K. Agar, Pete Driezen, Shannon Gravely, Anne C. K. Quah, Mary E. Thompson

\section{REFERENCES}

1. WHO Framework Convention on Tobacco Control. Electronic nicotine delivery systems. FCTC/COP/6/10. http://apps.who.int/gb/fctc/PDF/cop6/FCTC_ COP6_10-en.pdf. Accessed November 23, 2018.

2. World Health Organisation. WHO report on the global tobacco epidemic, 2015: Raising taxes on tobacco. http://apps.who. int/iris/bitstream/10665/178574/1/9789240694606_eng. pdf?ua=1\&ua=1. Published 2015. Accessed November 23, 2018.

3. European Commission. Special Eurobarometer 458: Attitudes of Europeans towards tobacco and electronic cigarettes. http://data.europa.eu/euodp/en/data/dataset/ S2146_87_1_458_ENG. Published 2017. Accessed November 23, 2018.

4. Hon L. Flameless electronic atomizing cigarette. US20060196518A1. Google Patents. https://www.google. com/patents/US20060196518. Published 2016. Accessed November 23, 2018.

5. Yong HH, Borland R, Balmford J, et al. Trends in E-Cigarette Awareness, Trial, and Use Under the Different Regulatory Environments of Australia and the United Kingdom. Nicotine Tob Res. 2015;17(10):1203-1211. doi:10.1093/ntr/ntu231

6. Eastwood B, East K, Brose LS, et al. Electronic cigarette use in young people in Great Britain 2015-2016. Public Health. 2017;149:45-48. doi:10.1016/j.puhe.2017.03.019

7. McNeill A, Brose LS, Calder R, Bauld L, Robson D. Evidence review of e-cigarettes and heated tobacco products 2018: A report commissioned by Public Health England. https://assets.publishing.service.gov.uk/ government/uploads/system/uploads/attachment_data/ file/684963/Evidence_review_of_e-cigarettes_and_ heated_tobacco_products_2018.pdf. Published February, 2018. Accessed November 23, 2018.

8. McAuley TR, Hopke PK, Zhao J, Babaian S. Comparison of the effects of e-cigarette vapor and cigarette smoke on indoor air quality. Inhal Toxicol. 2012;24(12):850-857. doi:10.3109/08958378.2012.724728

9. Royal College of Physicians. Nicotine without smoke: Tobacco harm reduction. Royal College of Physicians; 2016. https://www.rcplondon.ac.uk/projects/outputs/ nicotine-without-smoke-tobacco-harm-reduction-0. Accessed November 23, 2018.

10. McNeill A, Brose LS, Calder R, Hitchman SC, Hajek P, 
McRobbie H. E-cigarettes: an evidence update. A report commissioned by Public Health England. Public Health England; 2015. https://assets.publishing.service.gov.uk/ government/uploads/system/uploads/attachment_data/ file/733022/Ecigarettes_an_evidence_update_A_report_ commissioned_by_Public_Health_England_FINAL.pdf. Accessed November 23, 2018.

11. Lotrean LM, Mesters I, de Vries H. Why do Romanian junior high school students start to smoke? Child: Care, Health and Development. 2013;39:851-855. doi:10.1111/j.1365-2214.2012.01428.x

12. Conner M, Grogan S, Simms-Ellis R, et al. Do electronic cigarettes increase cigarette smoking in UK adolescents? Evidence from a 12-month prospective study. Tob Control. 2017;27:365-372. doi:10.1136/tobaccocontrol-2016-053539

13. Wang MP, Ho SY, Lo WS, Lam TH. Overestimation of peer smoking prevalence predicts smoking initiation among primary school students in Hong Kong. J Adolesc Health. 2011;48:418-420. doi:10.1016/j.jadohealth.2010.07.017

14. Hammond D, Fong GT, Zanna MP, Thrasher JF, Borland R. Tobacco denormalization and industry beliefs among smokers from four countries. Am J Prev Med. 2006;31(3):225-232. doi:10.1016/j.amepre.2006.04.004

15. Hitchman S, Fong GT, Zanna MP, Thrasher JF, Laux F. The Relation Between Number of Smoking Friends, and Quit Intentions, Attempts, and Success: Findings from the International Tobacco Control (ITC) Four Country Survey. Psychol Addict Behav. 2014;28(4):1144-1152. doi:10.1037/a0036483

16. Bledsoe LK. Smoking cessation: an application of theory of planned behavior to understanding progress through stages of change. Addict Behav. 2006;31(7):1271-1276. doi:10.1016/j.addbeh.2005.08.012

17. Otten R, Harakeh Z, Vermulst AA, Van den Eijnden RJ, Engels RC. Frequency and quality of parental communication as antecedents of adolescent smoking cognitions and smoking onset. Psychol Addict Behav. 2007;21(1):1-12. doi:10.1037/0893-164X.21.1.1

18. Sæbø G, Scheffels J. Assessing notions of denormalization and renormalization of smoking in light of e-cigarette regulation. International Journal of Drug Policy. 2017;49:58-64. doi:10.1016/j.drugpo.2017.07.026

19. East K, Hitchman SC, Stead M, Mackintosh AM, McNeill A. The development of tools to measure norms towards smoking, nicotine use, and the tobacco industry. phrc. lshtm.ac.uk/project_2011-2016_013.html. Published 2017. Accessed November 23, 2018.

20. Fairchild AL, Bayer R, Colgrove J. The renormalization of smoking? E-cigarettes and the tobacco 'endgame'. N Engl J Med. 2014;370(4):293-295. doi:10.1056/NEJMp1313940

21. Dawson CT, Maziak W. Renormalization and Regulation of E-Cigarettes. Am J Public Health. 2016;106(3):569. doi:10.2105/AJPH.2015.302992
22. Voigt K. Smoking norms and the regulation of e-cigarettes. Am J Public Health. 2015;105(10):19671972. doi:10.2105/AJPH.2015.302764

23. The European Parliament and the Council of the European Union. Directive 2014/40/EU Of The European Parliament And Of The Council. Official Journal of the European Union. https://ec.europa.eu/health/sites/ health/files/tobacco/docs/dir_201440_en.pdf. Published 2014. Accessed November 23, 2018.

24. World Health Organisation. Global Health Observatory data repository: Tobacco use Data by country. http:// apps.who.int/gho/data/node.main.65. Updated May 12, 2015. Accessed April 6, 2018.

25. Martinez-Sanchez JM, Fernandez E, Fu M, et al. Smoking behaviour, involuntary smoking, attitudes towards smoke-free legislations, and tobacco control activities in the European Union. PLoS One. 2010;5(11):e13881. doi:10.1371/journal.pone.0013881

26. East K, McDermott M, Hitchman SC, et al. Social Norms Towards Smoking and Electronic Cigarettes Among Adult Smokers in Seven European Counties: Findings from the International Tobacco Control (ITC) Project. osf.io/ c83pe. Published 2018. Accessed November 23, 2018.

27. Joossens L, Raw M. The Tobacco Control Scale 2016 in Europe. https://www.tobaccocontrolscale.org/ wp-content/uploads/2017/03/TCS-2016-in-EuropeCOMPLETE-LoRes.pdf. Published 2017. Accessed November 23, 2018.

28. International Tobacco Control Policy Evaluation Project. Countries. http://www.itcproject.org/countries/. Updated 2018. Accessed August 23, 2018.

29. Vardavas CI, Bécuwe N, Demjén T, et al. Study Protocol of European Regulatory Science on Tobacco (EUREST-PLUS): Policy implementation to reduce lung disease. Tob Induc Dis. 2018;16(Suppl 2:A2). doi:10.18332/tid/93305

30. Fong GT, Thompson ME, Boudreau C, et al. The Conceptual Model and Methods of Wave 1 (2016) of the EUREST-PLUS ITC 6 European Countries Survey. Tob Induc Dis. 2018;16(Suppl 2:A3). doi:10.18332/tid/99881

31. International Tobacco Control Project. ITC 6 European Country Survey: Wave 1 Technical Report. https://www. itcproject.org/files/ITC6E_Wave1_TechRpt[3].pdf. Published 2017. Accessed November 23, 2018.

32. International Tobacco Control Project. ITC Four Country Tobacco and E-cigarette Survey Wave 1 Technical Report. https://www.itcproject.org/files/4CE1_Technical_ Report-28Nov2017.pdf. Published 2017. Accessed November 23, 2018.

33. International Tobacco Control Project. ITC 6 European Country W1. Survey Code: 6E1. https://www.itcproject. org/files/ITC_6E1_CAPI_Eng_20Jan2017.pdf. Published 2017. Accessed November 23, 2018.

34. International Tobacco Control Project. ITC 4-Country E-Cig W1. Survey Code: 4CE1. http://www.itcproject. 
org/files/ITG_4CE1__web_Eng.pdf. Published 2017. Accessed November 23, 2018.

35. Heatherton TF, Kozlowski L, Frecker RC, Rickert W, Robinson J. Measuring the Heaviness of Smoking: using selfreported time to the first cigarette of the day and number of cigarettes smoked per day. Addiction. 1989;84:791-800. doi:10.1111/j.1360-0443.1989.tb03059.x

36. Statistical Software [computer program]. Version 15.0. College Station, TX: Stata Corporation; 2017.

37. Hiscock R, Bauld L, Amos A, Fidler JA, Munafo M. Socioeconomic status and smoking: a review. Ann N Y Acad Sci. 2012;1248:107-123. doi:10.1111/j.1749-6632.2011.06202.x

38. Ling PM, Neilands TB, Glantz SA. The effect of support for action against the tobacco industry on smoking among young adults. American Journal of Public Health. 2007;97(8):1449-1456. doi:10.2105/AJPH.2006.098806

39. Filippidis FT, Laverty AA, Mons U, Jimenez-Ruiz C, Vardavas CI. Changes in smoking cessation assistance in the European Union between 2012 and 2017: pharmacotherapy versus counselling versus e-cigarettes. Tob Control. 2018. doi:10.1136/tobaccocontrol-2017-054117

40. Lapinski MK, Rimal RN. An Explication of Social Norms. Communication Theory. 2005;15(2):127-147. doi:10.1093/ct/15.2.127

41. Thrasher JF, Quah ACK, Dominick G, et al. Using Cognitive Interviewing and Behavioral Coding to Determine Measurement Equivalence across Linguistic and Cultural Groups. Field Methods. 2011;23(4):439460. doi: $10.1177 / 1525822 \times 11418176$

\section{ACKNOWLEDGEMENTS}

The ITC 6 European Country Survey, a component of the EUREST-PLUS programme, is a Horizon 2020 project conducted by researchers from the six participating countries and the following institutional partners: the European Network on Smoking Prevention (Belgium), King's College London (United Kingdom), German Cancer Research Centre (Germany), Maastricht University (The Netherlands), National and Kapodistrian National and Kapodistrian University of Athens (Greece), Aer Pur Romania (Romania), European Respiratory Society (Switzerland), University of Waterloo (Canada), Catalan Institute of Oncology (Catalonia, Spain), Smoking or Health Hungarian Foundation (Hungary), Health Promotion Foundation (Poland), University of Crete (Greece), and Kantar Public Brussels (Belgium).

\section{CONFLICTS OF INTEREST}

The authors declare that they have no competing interests, financial or otherwise, related to the current work. A Herbec reports grants from Pfizer, outside the submitted work. $\mathrm{Cl}$ Vardavas reports that he is the Strategic Development Editor of TID and that there are no conflicts of interest with this current work. The rest of the authors have also completed and submitted an ICMJE form for disclosure of potential conflicts of interest.

\section{FUNDING}

The EUREST-PLUS project has received funding from the European Union's Horizon 2020 research and innovation programme under grant agreement No 681109 (CIV) and the University of Waterloo (GTF). Additional support was provided to the University of Waterloo by a foundation grant from the Canadian Institutes of Health Research (FDN-148477). GTF was supported by a Senior Investigator Grant from the Ontario Institute for Cancer Research. EF is partly supported by Ministry of Universities and Research, Government of Catalonia (2017SGR319) and by the Instituto Carlos III and co-funded by the European Regional Development Fund (FEDER) (INT16/00211 and INT17/00103), Government of Spain. The PhD of KE is funded by the UK Centre for Tobacco and Alcohol studies (MR/K023195/1). The UK Public Health Research Consortium funded the development of some of the social-norms measures included in this study.

\section{AUTHORS' CONTRIBUTIONS}

KE led the writing up of this manuscript and performed the data analyses reported, with input from $\mathrm{SH}$ and $\mathrm{AM}$. $\mathrm{SH}, \mathrm{MM}, \mathrm{AM}$ and $\mathrm{AH}$ provided input on the analysis plan. $\mathrm{SH}, \mathrm{MM}, \mathrm{AM}, \mathrm{AH}, \mathrm{MF}, \mathrm{EF}, \mathrm{UM}, \mathrm{AT}$ and $\mathrm{CV}$ reviewed and commented on manuscript drafts. $\mathrm{SH}, \mathrm{MM}, \mathrm{AM}$ $\mathrm{AH}, \mathrm{MF}$ and $\mathrm{AT}$ further reviewed and provided input on the manuscript following comments from reviewers. All authors were involved in the EUREST-PLUS project, including the design of the surveys and measures included in this manuscript.

PROVENANCE AND PEER REVIEW

Commissioned; externally peer reviewed. 